\section{SAT0155 TRADITIONAL AND NONTRADITIONAL CARDIOVASCULAR RISK FACTORS IN PATIENTS WITH EARLY ONSET ARTHRITIS OF THE PANLAR-EOA}

I. Acosta Colman ${ }^{1}$, P. Delgadillo ${ }^{2}$, G. Avila-Pedretti ${ }^{3}$, S. Cabrera-Villalba ${ }^{4}$, P. Melgarejo ${ }^{4}$, G. Elizaur ${ }^{4}$, M. Franco ${ }^{4}$, A. Ramagli $i^{5}$, J. Mazzoleni ${ }^{4}$, P. Abreu ${ }^{6}$. ${ }^{1}$ Departamento de Reumatologia, Hospital de Clinicas de la Facultad de Medicina de la Universidad Nacional de Asunción, ${ }^{2}$ Departamento del IPS, ${ }^{3}$ Departamento de Reumatología, ${ }^{4}$ Departamento de Reumatologia, Instituto de Previsión Social, Asunción, Paraguay, ${ }^{5}$ Departamento de Reumatologia, Presidente del grupo de estudio PANLAR-EOA, Montevideo, Uruguay, ${ }^{6}$ Sociedad Paraguaya de Reumatología, Asunción, Paraguay

Background: Inflammation plays a significant role in atherosclerosis and cardiovascular disease (CVD). Patients with chronic inflammatory diseases are at increased risk of CVD, but it is debated whether this association is causal or dependent on shared risk factors or inflammatory pathways.

Objectives: Identify the mScore value and the association between traditional and nontraditional cardiovascular risks factors (CVRF) in an early onset arthritis (PANLAR-EOA)

Methods: Prospective, longitudinal cohort study. Patients were protocoled according to the PANLAR-EOA project. For this analysis only patients with 12 and 24 months follow up were included. Patients were registered in REPANARC (www.panlareoa.org) database. The mScore evolution and the nontraditional CVRF linked to the disease (i.e. DAS28) association with the traditional CVRF (i. e. obesity) were studied. The Wilcoxon Test and the Spearman correlation test, depending on wether the variables were categorical or numerical, were utilized.

Results: Initially 136 patients with early onset arthritis were included, out of which 88 completed the 12 months follow up and 58 the 24 months one. There was a female predominance $86 \%(117 / 136)$ of patients, with a median age of 44.80 $\pm 14,47$ years. When comparing the change ratio of the values obtained with the mScore on the initial, the 12 months and 24 months visit, the results were not statistically significant ( $p=0.106$ at 12 months and $p=0.175$ at 24 months). An association between the elevated erithrosedimentation rate and obesity $(p=5.807 e-03)$ and diabetes $(\mathrm{p}=3.739 \mathrm{e}-02)$ was found in the initial visit. An association between elevated prednisone doses and high levels of total cholesterol (2.084e-02), high levels of diastolic blood pressure $(\mathrm{p}=1.967 \mathrm{e}-02)$ and low $\mathrm{HDL}$ values were observed (7.706e-03). At 12 months a significant association between obesity and high CRP ( $p=3.649 \mathrm{e}-02$ ) and between high glycaemia levels with elevated prednisone doses and high CRP levels $(p=2.549 \mathrm{e}-02)$. In the 24 months visit analysis, an association between elevated HDL-chol with high prednisone doses ( $p=5.016 \mathrm{e}-03$ ) and elevated CRP levels (3.492e-02)

Conclusions: An increment in Cardiovascular Risk (CVR) was not found at 12 and 24 months follow up according to the mScore. We have observed that there is an association between traditional and nontraditional CVRF. Therefore, the prevention strategies should be aimed not only towards the control of traditional CVRF, but also against the nontraditional CVRF associated with disease activity, which in a certain way could influence over the previous ones and modify the global CVR of patients with EOA

Disclosure of Interest: None declared

DOI: 10.1136/annrheumdis-2018-eular.4282

\section{SAT0156 ASSOCIATION BETWEEN CUMULATIVE METHOTREXATE DOSE, NON-INVASIVE SCORING SYSTEM AND HEPATIC FIBROSIS DETECTED BY FIBROSCAN IN RHEUMATOID ARTHRITIS PATIENTS RECEIVING METHROTREXATE.}

R. Lertnawapan ${ }^{1}$, S. Chonprasertsuk ${ }^{1}$, S. Siramolpiwat ${ }^{1} .{ }^{1}$ Dept.Medicine, Faculty of Medicine, Thammasat University, Bangkok, Thailand

Background: Methotrexate (MTX) is recommended by recent ACR and EULAR guideline as a first-line drug for RA. Liver fibrosis, which occurs as long-term side effect is one of the most concerns.

Objectives: To find the association between clinical parameters, cumulative MTX dosage, liver fibrosis scoring systems and the presence of liver fibrosis assessed by transient elastography (TE; Fibroscan ${ }^{\circledR}$ ).

Methods: Rheumatoid arthritis, prescribed MTX, patients had been evaluated of liver fibrosis with TE. Two subgroups of patients were compared: non-fibrosis and fibrosis $(\mathrm{TE}>7 \mathrm{kPa}$ ). Univariate and multivariate logistic regression analysis were performed to identify factors associated with liver fibrosis.

Results: One hundred and eight patients were recruited. Twenty-nine patients $(26.8 \%)$ were classified by transient elastography as liver fibrosis cases. The multivariate analysis demonstrated only the statistically significant of the association in $\mathrm{BMI}(\mathrm{OR}=1.217 ; 95 \% \mathrm{Cl} 1.048-1.414 ; \mathrm{P}=0.010)$; fatty liver $(\mathrm{OR}=2.318 ; 95 \% \mathrm{Cl}$ 0.584-9.189; $\mathrm{P}=0.232) ; \mathrm{ALT}(\mathrm{OR}=1.044 ; 95 \% \mathrm{Cl}=1.003-1.087 ; \mathrm{P}=0.036)$ and cumulative MTX dosage (OR $1.001 ; 95 \% \mathrm{Cl} 1.000-1.001 ; \mathrm{P}=0.001)$.

Conclusions: Liver fibrosis measured with Fibroscan was associated with cumulative MTX. RA patients with metabolic syndrome including high BMI, IFG, fatty liver had higher risk of MTX-induced hepatic fibrosis. RA patients with high cumulative MTX dose, especially patients with concurrent metabolic syndrome should be cautiously monitored for liver fibrosis.

Disclosure of Interest: None declared

DOI: 10.1136/annrheumdis-2018-eular.1392

\section{SAT0157 THE PREVALENCE OF DYSLIPIDEMIA AND DAILY NUTRITIONAL INTAKE IN RHEUMATOID ARTHRITIS PATIENTS: A STUDY OF THE KOREAN NATIONAL HEALTH AND NUTRITION EXAMINATION SURVEY (KNHANES)}

S. H. Joo ${ }^{1}$, Y. W. Song ${ }^{2,3} .{ }^{1}$ Division of Rheumatology Department of Internal Medicine, Jungang Medical Foundation, Jeju-si, ${ }^{2}$ Division of Rheumatology, Department of Internal Medicine, Seoul National University Hospital, ${ }^{3}$ Department of Molecular Medicine and Biopharmaceutical Sciences, Graduate School of Convergence Science and Technology, and College of Medicine, Medical Research Center, Seoul National University, Seoul, Korea, Republic Of

Background: Lipid metabolism appear to be changed in rheumatoid arthritis (RA) patients because of disease activity and inflammation.

Objectives: It was not clear in the previous studies that lipid profiles status is associated with nutritional intake in RA patients.

Methods: We analyzed RA, dyslipidemia, serum lipid profiles (total cholesterol, TG, HDL, and LDL) and nutritional intake data related lipid from the data of

Abstract Sat0156 - Table 1. The univariate and multivariate logistic regression analysis of factors associated with significant liver fibrosis.

\begin{tabular}{|c|c|c|c|c|c|c|}
\hline & Univariate & Logistic & Regression & Multivariate & Logistic & Regression \\
\hline Parameter & Odds ratio & $\begin{array}{l}\text { 95\% confident } \\
\text { interval }\end{array}$ & P-value & Odds ratio & $\begin{array}{l}95 \% \text { confident } \\
\text { interval }\end{array}$ & $\mathrm{P}$-value \\
\hline Body weight(kg) & 1.042 & $1.002-1.083$ & 0.039 & - & - & - \\
\hline BMI $\left(\mathrm{kg} / \mathrm{m}^{2}\right)$ & 1.266 & $1.107-1.449$ & 0.001 & 1.217 & $1.048-1.414$ & 0.010 \\
\hline IFG & 3.400 & $1.240-9.320$ & 0.017 & - & - & - \\
\hline Fatty liver & 3.652 & $1.114-11.971$ & 0.032 & 2.318 & $0.584-9.189$ & 0.232 \\
\hline HLP & 4.397 & $1.803-10.722$ & 0.001 & - & - & - \\
\hline RA duration (y) & 1.122 & $1.022-1.233$ & 0.016 & - & - & - \\
\hline MTX duration (wk) & 1.005 & $1.002-1.008$ & 0.001 & - & - & - \\
\hline $\begin{array}{l}\text { MTX cumulative dose } \\
(\mathrm{mg})\end{array}$ & 1.001 & $1.000-1.001$ & 0.000 & 1.001 & $1.000-1.001$ & 0.001 \\
\hline $\begin{array}{l}\text { Prednisolone dose }(\mathrm{mg} / \\
\text { d) }\end{array}$ & 2.235 & $0.939-5.319$ & 0.069 & - & - & - \\
\hline Statin & 3.391 & $1.374-8.370$ & 0.000 & - & - & - \\
\hline TJC & 1.305 & $1.012-1.682$ & 0.040 & - & - & - \\
\hline AST (IU/L) & 1.047 & $0.998-1.098$ & 0.058 & & & \\
\hline ALT (IU/L) & 1.040 & $1.008-1.074$ & 0.014 & 1.044 & $1.003-1.087$ & 0.036 \\
\hline GGT (IU/L) & 1.131 & $1.080-1.184$ & 0.000 & - & - & - \\
\hline INR & 48853.68 & $169.313-1.41 \mathrm{e}$ & 0.000 & - & - & - \\
\hline Ultrasound & 6.961 & $2.666-18.175$ & 0.000 & - & - & - \\
\hline AST/ALT ratio & 0.420 & $0.156-1.128$ & 0.085 & - & - & - \\
\hline
\end{tabular}


KNHANES ( $\mathrm{N}=22,948$, estimated population size $=48,402,221)$. We analyzed the prevalence of RA and abnormal status of lipid profiles using general linear model and logistic regression with complex sample design method adjusted by age and sex and evaluated the association between RA and dyslipidemia including nutritional intake data.

Results: The prevalence of RA was $1.21 \%$ [95\% Cl: 1.07-1.38]. The prevalence of dyslipidemia with RA (3.31\% [95\% Cl: 2.63-4.17]) was significantly increased compared with that of dyslipidemia without RA $(1.37 \%$ [95\% Cl: $1.17-1.59]$, $\mathrm{p}<0.001)$

LDL (RA vs. control: $117.77 \pm 3.87 \mathrm{mg} / \mathrm{dL}$ vs. $114.47 \pm 0.51 \mathrm{mg} / \mathrm{dL}, \mathrm{p}<0.001$ ) was significantly increased, whereas TG (RA vs. control: $129.21 \pm 6.38 \mathrm{mg} / \mathrm{dL}$ vs. $136.72 \pm 1.20 \mathrm{mg} / \mathrm{dL}, \mathrm{p}<0.001)$ was significantly decreased in RA. Total cholesterol tended to be higher in RA (RA vs. control: $198.12 \pm 3.09 \mathrm{mg} / \mathrm{dL}$ vs. 188.11 $\pm 0.39 \mathrm{mg} / \mathrm{dL}, \mathrm{p}=0.051$ ). but HDL (RA vs. control: $54.16 \pm 1.42 \mathrm{mg} / \mathrm{dL}$ vs. 52.46 $\pm 0.15 \mathrm{mg} / \mathrm{dL}, \mathrm{p}=0.98$ ) was not different between two groups.

There were no differences in nutritional intake volume including total diet volume, energy intake, water, carbohydrate, protein, fat, other fatty acids and dietary fiber (Table).

Table 1 Nutritional intake difference between RA and control

\begin{tabular}{|c|c|c|c|}
\hline & RA & control & $\mathrm{p}$ \\
\hline Total diet (g/day) & $1447.96 \pm 55.81$ & $1658.24 \pm 11.50$ & 0.40 \\
\hline Energy intake (kcal/day) & $1826.19 \pm 61.89$ & $2121.24 \pm 12.16$ & 0.87 \\
\hline Water (g/day) & $1027.92 \pm 46.74$ & $1182.23 \pm 9.66$ & 0.38 \\
\hline Protein (g/day) & $61.06 \pm 2.88$ & $74.71 \pm 0.58$ & 0.85 \\
\hline Carbohydrate (g/day) & $298.90 \pm 8.76$ & $318.72 \pm 1.64$ & 0.45 \\
\hline Fat $(\mathrm{g} /$ day $)$ & $36.66 \pm 2.46$ & $47.71 \pm 0.49$ & 0.72 \\
\hline Cholesterol (mg/day) & $207.17 \pm 33.49$ & $278.72 \pm 6.63$ & 0.62 \\
\hline Saturated fatty acid (g/day) & $10.05 \pm 0.77$ & $13.75 \pm 0.15$ & 0.95 \\
\hline \begin{tabular}{|l} 
Monounsaturated fatty acid ( $g /$ day) \\
\end{tabular} & $10.97 \pm 0.77$ & $15.17 \pm 0.18$ & 0.86 \\
\hline \begin{tabular}{|l} 
Polyunsaturated fatty acid (g/day) \\
\end{tabular} & $10.08 \pm 0.76$ & $11.94 \pm 0.14$ & 0.88 \\
\hline $\mathrm{n}-3$ fatty acid (g/day) & $1.59 \pm 0.19$ & $1.70 \pm 0.03$ & 0.46 \\
\hline $\mathrm{n}-6$ fatty acid (g/day) & $8.56 \pm 0.67$ & $10.31 \pm 0.12$ & 0.77 \\
\hline Crude fiber (g/day) & $8.53 \pm 0.71$ & $7.71 \pm 0.09$ & 0.74 \\
\hline Dietary fiber (g/day) & $23.85 \pm 1.62$ & $24.53 \pm 0.30$ & 0.25 \\
\hline
\end{tabular}

Adjusted by age, sex and body mass index

Conclusions: We showed increased prevalence of dyslipidemia patients in the individuals with RA than those without RA. Serum LDL levels was increased and TG was decreased in RA patients of the Korean population survey.

Disclosure of Interest: None declared

DOI: 10.1136/annrheumdis-2018-eular.6695

\section{SAT0158 THE ASSESSMENT OF SAFETY AND EFFICACY OF USING SELF-MONITORING OF DISEASE ACTIVITY VIA WEB PORTAL IN THE MANAGEMENT OF PATIENTS WITH RHEUMATOID ARTHRITIS}

G. Bagirova ${ }^{1}$, E. Lygina ${ }^{1}$, S. lakushin ${ }^{1}$, A. Vorobyev ${ }^{1} .{ }^{1}$ Ryazan State Medical University, Ryazan, Russian Federation

Background: According to the Treat-to-Target guidelines for the RA, the main goal of treatment is remission or, alternatively, a lower activity of the disease. However, persistent remissions and preservation of working capacity are observed in no more than $5-6 \%$ of cases. As a result of the analysis of possible causes of the strategy's lack of efficacy, it seemed to us urgent to create and approve the method of managing RA patients via the "Web portal for self-monitoring of rheumatoid arthritis activity".

Objectives: Maximally quickly identify the exacerbation of the disease and timely strengthen the therapy, for more rapid achievement of remission or low disease activity

Methods: The authors created an interactive web portal for self-monitoring of RA activity. The patient management model using this method is that a patient conducts a monthly self-evaluation of the disease activity and transmits this information to his treating doctor in a remote manner via the web portal. The doctor receives information about the patient's health as quickly as possible. In case of worsening and in the absence of any dynamics, according to the patient, he was invited to the center, where this information was verified by a doctor and, if necessary, correction of therapy was made. If, in the patient's opinion, there was an improvement, he did not come to clinic, but continued therapy. During the management of patients with RA using this method (1 year) initially and further regularly clinical, laboratory and radiological monitoring of efficacy and safety was conducted. Currently, 30 women with RA, age 57 (38; 71), who completed the 6month treatment period, are included in the study. All patients underwent a clinical examination, hand and feet X-ray, laboratory tests and assessment of the RA activity by DAS28 index. Initially, all patients were trained by a rheumatologist to carry out a self-assessment of tender and swollen joints according to the original author's technique "Structured curriculum for teaching RA patients self-monitoring of disease activity".

Results: During 6 months, there was a positive dynamics of the course of the disease, the activity of the RA by DAS 28 decreased. Initially, 5 patients $(16.7 \%)$ had high DAS activity, 24 - moderate (80\%), 1- low (3.3\%). After 6 months of treatment 8 patients $(26.7 \%)$ had low activity, $22(73.3 \%)$ achieved remission. The mean value of the DAS 28 index at the time of inclusion was $3.99(2.46 ; 5.78)$ and after 6 months of management $2.175(0.79 ; 4.31)$, a statistically significan decrease (Wilcoxon T-test $=5$ ). Initially, all patients received methotrexate at an average dose of $12.9 \mathrm{mg}(10 \mathrm{mg} ; 30 \mathrm{mg})$, at 6 months of follow-up, the average dose was $14.6 \mathrm{mg}(10 \mathrm{mg} ; 25 \mathrm{mg})$. An increasing the dose of methotrexate was required in $11(36.6 \%)$ patients. Analysis of clinical and laboratory parameters did not reveal statistically significant deviations.

Conclusions: The 6-month period of patient management via the "web portal for self-monitoring of rheumatoid arthritis activity" proved the possibility of achieving remission and low disease activity in all patients.

Disclosure of Interest: None declared

DOI: 10.1136/annrheumdis-2018-eular.7381

\section{SAT0159 THYROID FUNCTION IN EARLY VERSUS ESTABLISHED RHEUMATOID ARTHRITIS}

S. Hannawi ${ }^{1}$, H. Hannawi ${ }^{2}$, I. Al Salmi ${ }^{3} .{ }^{1}$ Rheumatology, ${ }^{2}$ Ministry of Health and Prevention of UAE, Dubai, United Arab Emirates, ${ }^{3}$ The Royal Hospital, Muscat, Oman

Background: Thyroid dysfunction is common in rheumatoid arthritis (RA). Subclinical hypothyroidism is the first most common, followed by clinical hypothyroidism. Thyroid dysfunction in RA had been found to increase the risk of cardiovascular disease. Subclinical hypothyroidism is defined as increased serum TSH concentration with normal serum free thyroxine (T4) level.

Objectives: The aim of this study was to compare the thyroid function in early RA patients (of less than one-year duration of RA symptoms) versus established RA patients (of more than or equal to one-year duration of RA symptoms)

Methods: We recruited 35 early RA patients (ERA) and 52 established RA patients attending specialized rheumatology clinic. All the patients had no clinica evidence of thyroid dysfunction. Patients with diabetes, pregnancy, renal and liver impairment were excluded. Fasting Free thyroxine (FT4), Free triiodothyronine (FT3), and thyroid stimulating hormone (TSH) were assessed in all the participants. t-test was used to compare the RA disease characteristics and the thyroid function between early and established RA. $P$ value of $<0.05$ was considered significant.

Results: Rheumatoid arthritis patients had been recruited through a specialized rheumatology clinic, 35 were with new onset rheumatoid arthritis (early RA; ERA of less than a year of RA symptoms onset) and 52 were with established RA (of more than a year of RA symptoms onset). The mean RA duration was $7.4 \pm 2.0$ months for ERA and $96 \pm 92$ months for the established RA group. There were no significant differences in age $(45.76 \pm 2.45$ years for ERA vs, established RA respectively, $\mathrm{p}=0.49$ ), or in gender distribution ( $31 \mathrm{~F}$ and $4 \mathrm{M}$ in ERA vs. $46 \mathrm{~F}$ and $6 \mathrm{M}$ in established $\mathrm{RA}, \mathrm{p}=0.9$ ) between the two groups.

ERA compared to the established RA group had more active RA as manifested by more swollen 28 - joints ( 5.7 vs 1.7 , respectively, $p=0.001$ ), more tender 28 -joints (17 vs 11 , respectively, $p=0.01$ ), higher DAS-28-ESR score (5.8 vs 4.5 , respectively, p0.0001), higher DAS 28-CRP score (5.1 vs. 3.9, respectively, $p=0.001$ ), and longer morning stiffness duration $(p=0.04)$. As well, ERA had lower HDL level (1.4 vs 1.2 , respectively, $\mathrm{p}=0.04$ ). On the other hand, established-RA patients had RA disease onset at an earlier age than the EAR group (36.5 vs 44 years, respectively, $\mathrm{p}=0.02$ )

While the mean TSH, T3 and T4 were within normal range in both groups, there were significant differences in the mean values between ERA and established RA. TSH was $2.12 \pm 1.52$ in ERA vs. $5.8 \pm 8.3$ in established RA (NR:0.27-4.2 mlU/ $\mathrm{L}), \mathrm{p}=0.04$. Mean $\mathrm{FT} 3$ was $4.54 \pm 0.53$ in ERA vs. $3.61 \pm 1.13$ in the established RA (NR: $4-6.8 \mathrm{pmol} / \mathrm{L}$ ), $\mathrm{p}=0.04$. Average FT4 was $17.7 \pm 4.77$ in ERA vs. $15.3 \pm 2.51$ in the established RA (NR: 12-22 pmol/L), $p=0.01$.

Conclusions: RA patients with more than a year of RA symptoms are at a higher risk of silent autoimmune thyroid disease than their age sex matched RA patients with new onset RA; of less than a year of RA symptoms onset. Regular assess ment of thyroid function might be an important part in the routine biochemical and immunological profile screening of RA.

Disclosure of Interest: None declared

DOI: 10.1136/annrheumdis-2018-eular.4245 